\title{
Differences between tree species in hydraulic press calibration of leaf water potential are correlated with specific leaf area
}

\author{
E. RAYMOND HUNT, JR, JAMES A. WEBER \& DAVID M. GATES Biological Station and Matthaei \\ Botanical Gardens, University of Michigan, Ann Arbor, Michigan 48109, U.S.A.
}

Received 26 March 1984; accepted for publication 16 May 1984

\begin{abstract}
To determine the usefulness of the J-14 Hydraulic Press (Campbell Scientific, Inc., Logan, Utah, U.S.A.) in estimating leaf water potential, we calibrated the J-14 Press against a Scholander-type pressure chamber for leaves of various tree species. The species tested were: Acer saccharum, Acer negundo, Acer rubrum, Populus tremuloides, Populus grandidentata, Quercus rubra, and Brassaia actinophylla (Schefflera). The regression calibrations were linear with standard errors about the regression less than $0.1 \mathrm{MPa}$. The regression equations for the four genera were significantly different, with the $y$ intercept increasing and the slope decreasing in order of decreasing specific leaf area (SLA). There were no significant differences between species of the calibration lines within the genera Acer and Populus. These data may indicate that leaves with lower SLA resist mechanical compression by the hydraulic press, causing the J-14 Press to be less sensitive to differences of leaf water potential. Therefore the J-14 Press is only a relative measure of leaf water status and does not measure leaf water potential.
\end{abstract}

Key-words: Acer saccharum; Acer negundo; Acer rubrum; Populus tremuloides; Populus grandidentata; Quercus rubra; Brassaia actinophylla (Schefflera); J-14 Press; xylem pressure potential; specific leaf area.

\section{Introduction}

The measurement of leaf water potential is an important step to the understanding of leaf water status in relation to the environment. The Scholander-type pressure chamber (Scholander et al., 1965 ) is the standard apparatus for determining leaf water potential in the field (Ritchie \& Hinckley, 1975). The J-14 Hydraulic Press from Campbell Scientific, Inc. (Logan, Utah, U.S.A.) is potentially an inexpensive, simple, and portable method for the estimation of leaf water potential. Unlike the Scholander pressure chamber, the J-14 Press does not require a compressed air tank and can use leaf discs as well as intact leaves. Only a few comparisons between these two techniques have been published. Rhodes \& Matsuda (1976) found linear relationships between the $\mathrm{J}-14$ pressure and leaf water potential

Correspondence: E. Raymond Hunt, Jr, Biological Station, University of Michigan, Ann Arbor, MI 48109, U.S.A. for five herbaceous species equilibrated to $\mathrm{NaCl}$ solutions of various osmotic potentials. ShayoNgowi \& Campbell (1980) found a linear relationship of leaf matric potential between the J-14 Press and a pressure chamber. However, in a direct comparison between the J-14 Press and a pressure chamber, Bristow, Van Zyl \& De Jager (1981) found an exponential relationship between $\mathrm{J}-14$ pressure and chamber pressure. Campbell et al. (1979) inferred that all of the mechanical pressure applied to the cell walls, by the J-14 Press, is transmitted to the water in the cell wall.

The aim of this study was to reassess the relationship between the $\mathrm{J}-14$ pressure and leaf water potential as measured by the pressure chamber, for various tree species. Since the J-14 Press mechanically compresses the sample, we hypothesize that leaves with more structural rigidity should be more resistant to compression, resulting in a reduction in the sensitivity of the J-14 Press to differences in leaf water potential. To test this hypothesis, we chose various tree species on a subjective basis to cover a wide range of leaf rigidities. As a quantitative measure of leaf rigidity in these species, we used specific leaf area (SLA) and leaf thickness as an estimate of the amount of structural material present, chiefly fibre. While specific leaf area is not a direct estimate of the amount of fibre in mesophyllous leaves (Loveless, 1961), it was a quick and easy method of quantifying dry matter distribution in a leaf. Other means to measure leaf rigidity could possibly be used in the future (Heathcote, Etherington \& Woodward, 1979).

\section{Materials and methods}

The instruction manual for the J-14 Press (Campbell Scientific, Inc., Logan, Utah, U.S.A.) recognizes three endpoints for determining leaf water status:

1. a small amount of water appears at the cut edge or stem;

2. the leaf colour darkens, more water is exuded from the cut end, and water is exuded from the uncut edge as well;

3. the leaf turns almost black and copious water is exuded.

We used the second endpoint for all J-14 pressure 
measurements, as was used previously (Rhodes \& Matsuda, 1976; Bristow et al., 1981). There was difficulty in determining the second endpoint, therefore all J-14 measurements were obtained by one person for consistency. The J-14 Press was calibrated by first measuring the xylem pressure potential (Ritchie \& Hinckley, 1975) of a single leaf with a PMS Pressure Chamber (PMS Instruments, Corvallis, Oregon, U.S.A.). After slowly depressurizing the pressure chamber, the leaf was transferred to the J-14 Press for measurement. We tested the calibration procedure in two ways. First, we remeasured the xylem pressure potential of many leaves and obtained the same xylem pressure potential as the initial measurement. Second, we measured only the $\mathrm{J}-14$ pressure on one leaflet of Acer negundo, and on the opposite leaflet, we calibrated the J-14 Press as above. Under the assumption that the water potentials of opposite leaflets were equal, we performed a pairwise $t$-test and found no significant differences of J-14 pressure between leaflets $(t=-0.8$, d.f. $=14)$. With both controls, we concluded that our procedure is sufficient for the accurate calibration of the J-14 Press.

We calibrated the J-14 Press for seven tree species: Acer saccharum Marsh., Acer rubrum L., Acer negundo L., Populus tremuloides Michx., Populus grandidentata Michx., Quercus rubra L., and Brassaia actinophylla Endl. (Schefflera), in the field and in the laboratory at the Matthaei Botanical Gardens (University of Michigan, Ann Arbor, Michigan, U.S.A.). Individuals of A. saccharum, A. rubrum, $P$. tremuloides, and $P$. grandidentata were found in full sun in the field, of $Q$. rubra and $A$. negundo were in the shade in the field, and of $B$. actinophylla were from a greenhouse in full sun. The lower xylem pressure potentials were from measurements done in the field, whereas the high xylem pressure potentials usually were obtained using leaves from branches brought into the laboratory, recut under water, and left overnight.

Specific leaf area (leaf area/dry leaf mass) was calculated for 10 leaves of each species. Leaf area was measured with a LI-3000 area meter (LI-COR, Lincoln, Nebraska). Dry leaf mass was measured after drying at $70-75^{\circ} \mathrm{C}$ for $48 \mathrm{~h}$. Leaf thickness was measured between the major leaf veins using a micrometer precise to 0.0001 inch, on greenhousegrown tree seedlings of one species from each of the four genera.

All statistical tests were made using the Michigan Interactive Data Analysis System (MIDAS) written by the Statistical Research Laboratory (University of Michigan, Ann Arbor, Michigan, U.S.A.). In all statistical tests, the level of significance was 0.05 .

\section{Results and discussion}

Regression coefficients and statistics for the J-14 Press calibrations against a pressure chamber are shown in Table 1 for the data plotted in Figs 1-4. For each species, the standard error about the regression (Table 1) is less than $0.1 \mathrm{MPa}(1$ bar), which is similar to the standard errors calculated by Shayo-Ngowi \& Campbell (1980). The standard errors (Table 1) are also small compared to the calibration of the pressure chamber by thermocouple psychrometers (Ritchie \& Hinckley, 1975). The three regression lines for the three species of Acer are not significantly different from each other when tested by an $F$-test for regression equality $(F=1.480$, d.f. $=4$, 74). The pooled regression equation (Table 1 ) is plotted in Fig. 1. The residuals have constant variance and are normally distributed for the regression equations of the Acer species pooled, Q. rubra, and B. actinophylla. This shows that a linear relationship is the best relationship between $\mathrm{J}$ 14 pressure and chamber pressure. The data for $P$. grandidentata and $P$. tremuloides (Fig. 2) are fitted

Table 1. The regression coefficients and summary statistics for each species shown in Figs 1-4. Shown in order are the number of points $(n)$, the goodness-of-fit $\left(R^{2}\right)$, the standard error about the regression (SE), $y$-intercept ( \pm SE of intercept), the slope ( \pm SE of slope), and specific leaf area (SLA, $\left.\mathrm{cm}^{2} \mathrm{~g}^{-1}\right)$ ( \pm standard deviation). The SLA is based on 10 leaves and the letter following indicates significance based on simultaneous Scheffe confidence intervals. Species followed by the same letter are not significantly different at $P=0.05$

\begin{tabular}{lcccccc}
\hline Species & $n$ & $R^{2}$ & SE & $y$-Intercept & Slope & SLA \\
\hline Acer negundo & 17 & 0.664 & 0.0785 & $0.133 \pm 0.051$ & $0.622 \pm 0.121$ & $371.3 \pm 27.0^{a}$ \\
A. rubrum & 33 & 0.921 & 0.0398 & $0.114 \pm 0.022$ & $0.761 \pm 0.041$ & $212.0 \pm 64.5^{b}$ \\
A. saccharum & 30 & 0.958 & 0.0636 & $0.141 \pm 0.022$ & $0.677 \pm 0.027$ & $176.2 \pm 18.4^{b}$ \\
Acer spp. pooled & 80 & 0.930 & 0.0612 & $0.135 \pm 0.013$ & $0.691 \pm 0.021$ & \\
Populus tremuloides & & & & & & \\
P. grandidentata & 40 & 0.955 & 0.0804 & $0.442 \pm 0.019$ & $0.432 \pm 0.015$ & $142.6 \pm 21.4^{c}$ \\
Populus spp. pooled & 18 & 0.953 & 0.0568 & $0.410 \pm 0.018$ & $0.460 \pm 0.026$ & $137.3 \pm 30.0^{c}$ \\
Quercus rubra & 58 & 0.957 & 0.0737 & $0.431 \pm 0.014$ & $0.439 \pm 0.012$ & \\
Brassaia actinophylla & 53 & 0.848 & 0.0844 & $0.449 \pm 0.026$ & $0.321 \pm 0.019$ & $142.5 \pm 13.4^{c}$ \\
\hline
\end{tabular}




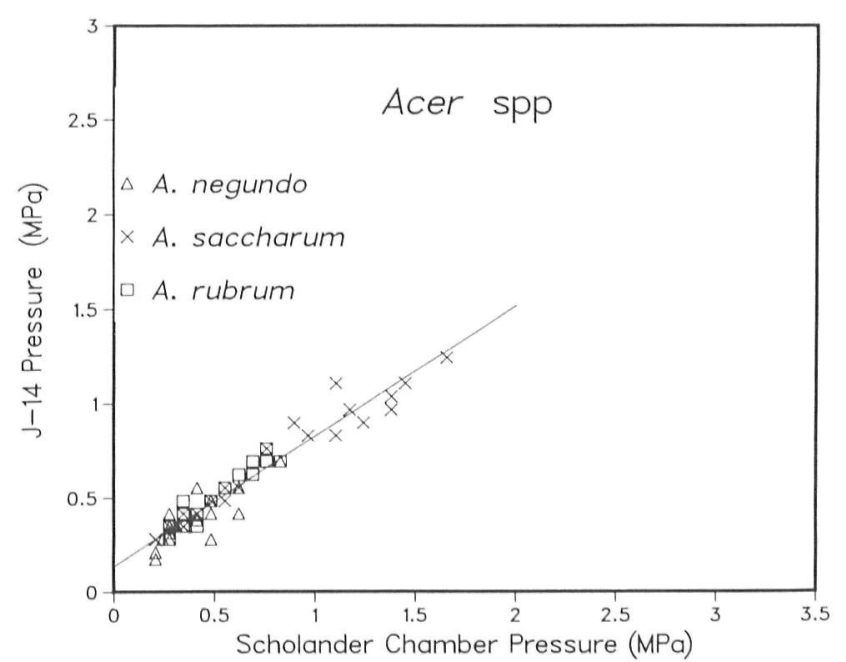

Figure 1. Calibration of the J-14 Press using a Scholander-type pressure chamber for three species of Acer. The negative of the Scholander chamber pressure is the xylem pressure potential. The line shown is the pooled least-squares regression line with coefficients shown in Table 1.

best by a second-order polynomial curve $\left(R^{2}=0.970\right)$, which is only slightly better than a linear relationship $\left(R^{2}=0.957\right.$, Table 1$)$. The residuals do not provide a definitive basis for choosing one relationship over the other, so we chose a linear relationship for comparison with the other species. The regression lines for the two Populus species were not significantly different from each other when tested by an $F$-test for regression equality $(F=0.172$, d.f. $=2,54)$. The pooled regression equation (Table 1) is plotted in Fig. 2. We did not find an exponential relationship as was found by Bristow et al. (1981).

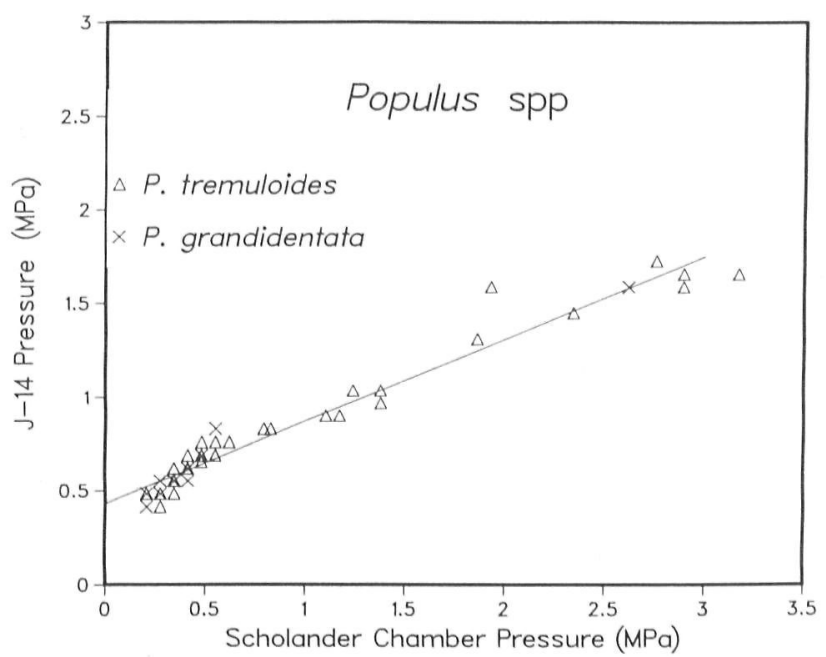

Figure 2. Calibration of the J-14 Press using a Scholander-type pressure chamber for two species of Populus. The negative of the Scholander chamber pressure is the xylem pressure potential. The line shown is the pooled least-squares regression line with coefficients shown in Table 1.

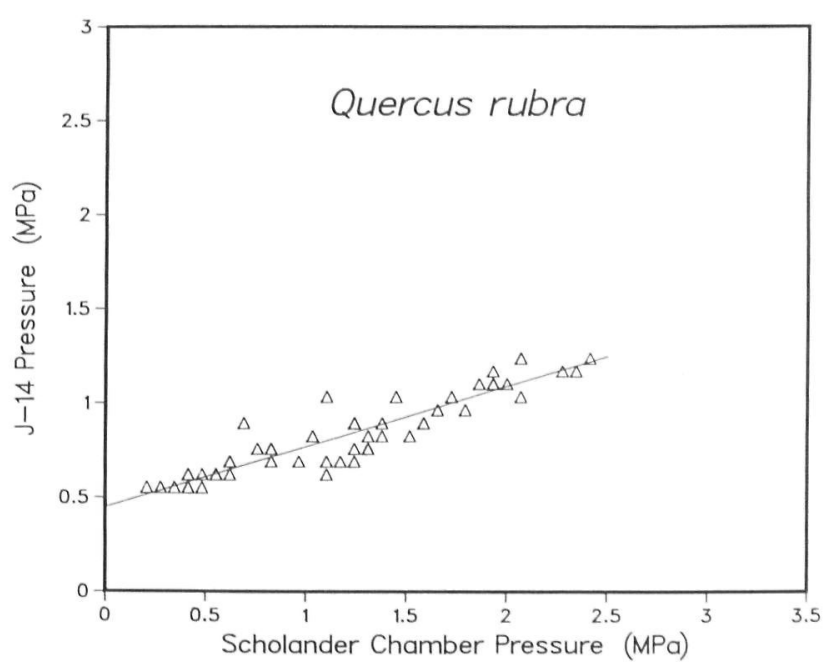

Figure 3. Calibration of the J-14 Press using a Scholander-type pressure chamber for Quercus rubra. The negative of the Scholander chamber pressure is the xylem pressure potential. The line shown is the least-squares regression line with coefficients shown in Table 1.

There are significant differences between the slopes of the regression equations of the four genera (Table 1). The $y$-intercepts are also significantly different from each other, except for the two Populus species and Q. rubra (Table 1). The orders of increasing slope and decreasing $y$-intercept are the same: Acer species, Populus species, Q. rubra, and B. actinophylla. The order of decreasing SLA is: Acer species, Q. rubra, Populus species, and B. actinophylla (Table 1). The differences in SLA between the Populus species and Q. rubra are not significant (Table 1). Specific leaf area depends both on leaf thickness and leaf fibre content. Populus leaves are

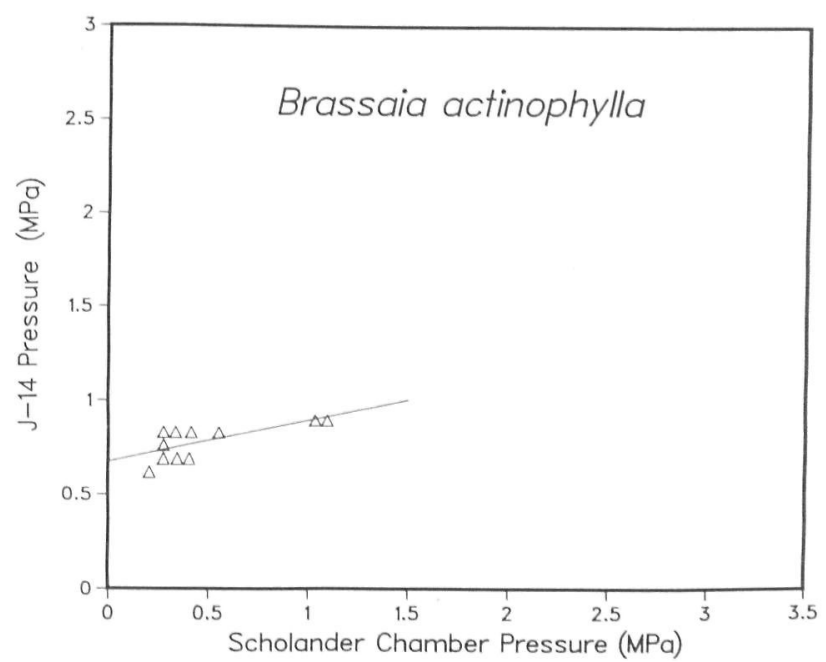

Figure 4. Calibration of the J-14 Press using a Scholander-type pressure chamber for Brassaia actinophylla (Schefflera). The negative of the Scholander chamber pressure is the xylem pressure potential. The line shown is the least-squares regression line with coefficients shown in Table 1 . 
thicker than Q. rubra leaves (mean thickness of $0.23 \mathrm{~mm}$ and $0.13 \mathrm{~mm}$, respectively); therefore Q. rubra leaves have less volume per unit dry leaf mass. The qualitative order for increasing leaf rigidity, estimated by SLA and leaf thickness, is: Acer species, Populus species, Q. rubra, and B. actinophylla, the same order as increasing $y$ intercept and decreasing slope (Table 1). These results support our hypothesis that rigid leaves, estimated by SLA and leaf thickness, should resist compression and should result in the J-14 Press being less sensitive to changes in xylem pressure potential of these leaves. It is important to note that the species used in our studies have similar morphology. The response of other types of leaves will probably be different.

We tried to measure the J-14 pressure of Chamaedaphne calyculata L. (Bog leatherleaf), but could not exert enough pressure to reach the second endpoint, although the xylem pressure potentials ranged from -0.5 to $-1.0 \mathrm{MPa}$. This also supports our hypothesis because C. calyculata leaves have a very low SLA.

We also regressed the Scholander chamber pressure as a function of $\mathbf{J}-14$ pressure to determine the ability of the J-14 Press to predict xylem pressure potential. The standard error about the regression ranged from $0.084 \mathrm{MPa}$ for the Acer species to $0.242 \mathrm{MPa}$ for Q. rubra, with Populus species and B. actinophylla in between. Thus, the predictive ability of the J-14 Press to estimate leaf water potential may be adequate for species with high SLA but inadequate for species with low SLA.

In conclusion, the J-14 Press alone cannot measure water potential, but can only give a relative measure of water status within a species, because leaf morphology affects the calibration curve by shifting the $y$-intercept and slope. G. S. Campbell (personal communication) reached the same conclusion but for different reasons. This finding limits the usefulness of the J-14 Press because one cannot compare species or possibly even growth conditions (e.g. sun and shade leaves) unless the instrument is calibrated by a technique that measures water potential directly. However, because the differences of the calibration lines are not significant between species within the Acer and Populus genera (Table 1), this limitation may not be serious under some conditions, where an estimate of relative water status is sufficient.

\section{Acknowledgments}

We thank Paul E. Marshall for valuable discussions and for use of the PMS Pressure Chamber. We also thank the Staff of the Matthaei Botanical Gardens for providing plant material and assistance. This research was sponsored by the U.S. Department of Energy, grant number DOE-ACO 2 -79EV10091 to David M. Gates.

\section{References}

Bristow, K.L., Van Zyl, W.H. \& De Jager, J.M. (1981) Measurement of leaf water potential using the J-14 Press. Journal of Experimental Botany, 32, 851-854.

Campbell, G.S., Papendick, R.I., Rabie, E. \& Shayo-Ngowi, A.J. (1979) A comparison of osmotic potential, elastic modulus, and apoplastic water in leaves of dryland winter wheat. Agronomy Journal, 71, 31-36.

Heathcote, D.G., Etherington, J.R. \& Woodward, F.I. (1979) An instrument for non-destructive measurement of pressure potential (tugor) of leaf cells. Journal of Experimental Botany, 30, $811-816$

Loveless, A.R. (1961) A nutritional interpretation of sclerophylly based on differences in the chemical composition of sclerophyllous and mesophyllous leaves. Annals of Botany, 25, $168-184$.

Rhodes, P.R. \& Matsuda, K. (1976) Water stress, rapid polyribosome reductions and growth. Plant Physiology, 58, 631-635.

Ritchie, G.A. \& Hinckley, T.M. (1975) The pressure chamber as an instrument for ecological research. Advances in Ecological Research, 9, 165-254.

Scholander, P.F., Hammel, H.T., Bradstreet, E.D. \& Hemmingsen, E.A. (1965) Sap pressure in vascular plants. Science, 148, 339-346.

Shayo-Ngowi, A. \& Campbell, G.S. (1980) Measurement of matric potential in plant tissue using the hydraulic press. Agronomy Journal, 72, 567-568. 
This document is a scanned copy of a printed document. No warranty is given about the accuracy of the copy. Users should refer to the original published version of the material. 